\title{
Lifetimes of Buildings in Japan
}

\section{Chihiro Kayo ( $\nabla$ kayoc@cc.tuat.ac.jp )}

Tokyo University of Agriculture and Technology

Mario Tonosaki

Forestry and Forest Products Research Institute

\section{Research Article}

Keywords: Lifetimes of Buildings, Japan, distribution, stock flow, environmental impacts, predictions and effective measures, climate change

Posted Date: October 25th, 2021

DOI: https://doi.org/10.21203/rs.3.rs-968275/v1

License: (1) This work is licensed under a Creative Commons Attribution 4.0 International License. Read Full License 


\section{Abstract}

Ascertaining the lifetime distribution of a nation's buildings is critical for estimating their stock flow, determining their environmental impacts, and exploring future predictions and effective measures. It is particularly necessary in climate-change-mitigating measures such as the estimation of wood carbon stock dynamics. This work uses the latest data on building stocks and inflows to identify the lifetime function and half-life of all wooden and non-wooden buildings existing in Japan from 1964-2020. The log-normal distribution of wooden buildings proved to be the most suitable lifetime function, with a half-life of 38 years in 1964, 56 years between 1965 and 1996, and 63 years between 1997 and 2020. On the other hand, the log-normal distribution resembled exponential distribution (first order decay) and was the most suitable for non-wooden buildings, with half-life of 22 years in 1964, 33 years between 1965 and 1990, and 52 years between 1991 and 2020. The lifetimes of both wooden and non-wooden buildings have increased over the course of the past half-century. It is important that future research uses these lifetime functions to explore future predictions of building stock based on new building demand, changes in lifetime, and effective climate change measures.

\section{Introduction}

Ascertaining building lifetimes at the national scale is critical for estimating building stock flow and the resulting environmental impacts, and to explore future predictions and effective measures [1,2]. Regarding climate-change mitigation in particular, a large amount of carbon is stored in the wood used in building construction [3-7]; therefore, it is essential to estimate the lifetime distribution of buildings across the nation to ascertain its carbon balance, make predictions about its effects, and take measures to tackle its drawbacks.

Studies on building lifetime estimation have been carried out in various countries, including the United States [8-11], United Kingdom [8, 12], Finland [13], Norway [14], Germany [15, 16], the Czech Republic [16], Austria [17], and China [18-20]. While Japan has also made significant progress in this area [12, 21-25], building lifetime estimation has been restricted to the urban level; few studies have analyzed this on a national scale, with even such studies being outdated by 30 years [26] and not accounting for differences in building structure [26, 27].

Additionally, the amount of wood used per unit floor area of a wooden building is approximately ten times that of non-wooden buildings [28, 29]; therefore, accurately distinguishing between wooden and non-wooden buildings is necessary to estimate the amount of wood carbon stock in Japanese buildings.

For Japan, the available statistical data, including data on the floor area of existing building stock [30,31], directly enable the determination of building stock for different types of structures all over the country. Because these data serve as the basis for property taxes, they are highly reliable. Statistical data on building inflow is also available, which is the floor area of newly started construction work each year [32]. By comparing these statistical values for stock and inflow, it is possible to estimate the distribution of building lifetimes throughout Japan for each type of structure; however, to the best of the authors' knowledge, no existing work has investigated these aspects.

Therefore, the purpose of this study is to estimate the lifetime distribution of wooden and non-wooden buildings all over Japan by modelling building stock over the years using its inflow and lifetime function. Specifically, this means multiple explorations of the lifetime functions of wooden and non-wooden buildings and their average lifetime (half-life), which is a parameter thereof, as well as determining the lifetime function and half-life most suited to statistical values of stock from 1964-2020, which is the period for which statistical data are available. Furthermore, we also used these results to estimate the amount of carbon stock in the wood used in all the buildings throughout Japan for the same period.

\section{Methods}

\section{Target period, buildings, and statistical data}

The target period was 1964 to 2020, a period during which statistical data [30-32] on buildings in Japan was available for compilation. In addition, the target buildings were divided into wooden and non-wooden buildings throughout Japan.

Statistical data on existing building floor area [30,31], which represents the amount of stock, were divided into taxable and non-taxable. While there were data available on taxable buildings in terms of whether they were wooden or non-wooden, no structural data on non-taxable buildings could be obtained. Therefore, we used the percentages of wooden and non-wooden taxable building floor areas for each year and proportionally divided the non-taxable building floor area between wooden and non-wooden. The percentage of all building floor areas during the target period that was non-taxable was $4 \%-9 \%$, and thus more than $90 \%$ was taxable. In addition, values that were recorded for the nontaxable building floor area in 1973 were approximately double of those in the years before and after that year, which was deemed as an abnormality in terms of statistical data. Therefore, we used the average value of the years before and after 1973. Supplementary Table S6 and Fig. S1(a) show the statistical data for the existing building floor area during the target period for wooden and non-wooden buildings. 
Statistical data on the new building floor area [32], which represents the amount of inflow, was acquired for wooden and non-wooden buildings. Furthermore, data were available on detailed structural categories of non-wooden buildings in the same statistics, including reinforced concrete construction, steel-framed reinforced concrete construction, and steel-framed construction. However, statistical data [30, 31] on detailed categories were not obtained for the building stock during the target period, and little difference was found when comparing the amount of wood used in non-wooden buildings to wooden buildings per these detailed categories [28, 29]. Therefore, we used statistical data batching together with non-wooden buildings to determine the amount of building inflow. Supplementary Table S6 and Fig. S1(b) show the statistical data on the new building floor area during the target period for wooden and non-wooden buildings.

\section{Method of estimating amount of stock}

We decided to determine the amount of building stock using equation (1). In addition, the amount of carbon stock in wood used in buildings can be determined by equation (2).

$$
\begin{gathered}
S_{i}(t)=S\left(t_{0}\right) \cdot\left(1-R_{0}\left(t-1-t_{0}\right)\right)+\sum_{i=t_{0}}^{t-1}\left[F_{i} \cdot(1-R(t-1-i))\right] \\
C S_{i}(t)=S_{i}(t) \cdot W_{i} \cdot D \cdot C
\end{gathered}
$$

Here, $S_{i}(t)$ indicates the existing building floor area $\left(\mathrm{m}^{2}\right)$ built in year $i$ at the start of year $t, S\left(t_{0}\right)$ is the existing building floor area $\left(\mathrm{m}^{2}\right)$ at the start of the initial year $t_{0}, F_{i}$ indicates the new building floor area $\left(\mathrm{m}^{2} / \mathrm{yr}\right)$ built during year $i, R_{0}\left(t-1-t_{0}\right)$ indicates the building lifetime function (cumulative distribution function of lifetime distribution) for the years elapsed from the initial year $t_{0}$ to year $t-1$, and $R(t-1-i)$ indicates the lifetime function of a building for the years elapsed from year $i$ to year $t-1$. $C S_{i}(t)$ indicates the amount of carbon stock (Mg-C) in wood used in existing buildings built in year $i$ at the start of year $t, W_{i}$ indicates the amount of wood used per unit floor area $\left(\mathrm{m}^{3} / \mathrm{m}^{2}\right)$ in buildings built during year $i$, $D$ indicates the density of wood (oven dry mass over air dry volume) $\left(\mathrm{Mg} / \mathrm{m}^{3}\right)$, and $C$ indicates the carbon content of oven-dried wood (Mg-C/Mg). Furthermore, the initial year $t_{0}$ is 1964, and year $t$ is each year until 2020.

The statistical data $(B(t))[30,31]$ on the existing building floor area during the target period is not published for each new construction building year; thus, $S_{i}(t)$ on the left side of equation (1) cannot be directly ascertained. On the other hand, because the amount of wood used in buildings fluctuates according to the building year, the existing building floor area per building year $\left(S_{i}(t)\right)$ and the amount of wood used per building year $\left(W_{i}\right)$ must be used according to the right side of equation (2) to make a precise estimation. Hence, we substituted statistical data for the existing building floor area in the initial year of 1964 ( $B(1964)$ ) [30] into $S\left(t_{0}\right)$ on the right side of equation (1), and determined the parameters of the lifetime functions $\left(R_{0}, R\right)$, such that the estimated value $S_{i}(t)$ determined by conferring statistical data on the new building floor area [32] on $F_{i}$ fits the statistical value $B(t)$. In addition, because the existing buildings $\left(S\left(t_{0}\right)\right)$ in the initial year (1964) is an accumulation of all buildings that were constructed beforehand, they decrease with the passage of years. However, because it is not possible to ascertain the existing buildings per building year from statistical data, we could not craft a model based on new buildings and the lifetime function indicated by the second term on the right side of equation (1). Therefore, we decided to regard $S\left(t_{0}\right)$ as a single building group and established a model that decreased according to the lifetime function $R_{0}$, indicated by the first term on the right side of equation (1).

If the lifetime functions $\left(R_{0}, R\right)$ of equation (1) can be identified by the above method, then it is also possible to make future predictions of the amount of building stock and the amount of wood carbon stock based upon these lifetime functions by conferring future scenarios on the amount of future building inflow $\left(F_{i}\right)$ and lifetime $(R)$.

The amount of wood used per unit floor area $\left(W_{i}\right)$ in equation (2) is applied to products containing roundwood, sawn wood, plywood, and wood board. For roundwood, sawn wood, and plywood, we cited statistical data [44] for wooden and non-wooden buildings surveyed every two-three years during the target period from 1976 to 2017. For years lacking in statistical values, we decided to use statistical values from 1976 for the years prior to 1975, and henceforth statistical values from the immediately preceding year. On the other hand, for wood boards (particle board, hardboard, medium-density fiberboard, insulation board), although we cited values from previous research [29] used every three years for the period 1976-2012, it was assumed that there were no structural differences between wooden and non-wooden buildings as it was not possible to ascertain the amount of use per wooden and non-wooden buildings. Years lacking in reported values were handled in a manner similar to the statistical values for roundwood, sawn wood, and plywood described above. We used the numerical values in Table 12.1 and 12.2 from the IPCC 2019 Refinement [35] per wood product for carbon conversion factors $D$ and $C$.

\section{Lifetime function}


Previous research on lifetime functions $\left(R_{0}, R\right)$ mainly examined exponential distribution (FOD) $[3,10,13,33-35]$, logistic distribution $[4,5,28]$, normal distribution [1, 2, 12, 14, 16, 21-23, 26], log-normal distribution [9, 12, 21-23, 26, 41, 42], Weibull distribution [9, 12, 14, 17-20, 21-23, 42], and Gamma distribution $[3,9,10,12]$, and these six types of functions were also studied. However, for the logistic and normal distributions, we used a function normalized by setting the remaining ratio $(1-R(t-1-i))$ of zero elapsed years $(t-1=i)$ to 1 .

We determined the parameter for minimizing the residual sum of squares $(E)$ between the statistical value $B(t)$ and the estimated value $S_{i}(t)$ of the existing building floor area for each lifetime function according to equation (3).

$$
E=\sum_{t}\left(B(t)-S_{i}(t)\right)^{2}=\sum_{t}\left(B(t)-\left\{S\left(t_{0}\right) \cdot\left(1-R_{0}\left(t-1-t_{0}\right)\right)+\sum_{i=t_{0}}^{t-1}\left[F_{i} \cdot(1-R(t-1-i))\right]\right\}\right)^{2}
$$

\section{Half-life}

We defined the lifetime function parameter of half-life as the number of years elapsed at which the remaining fraction $(1-R(t-1-i))$ reached 0.5. We then examined both cases: we set a single half-life (and other parameters) assuming that the building half-life (and other parameters) did not change throughout the entire target period, and cases in which we set multiple half-lives (and other parameters) assuming that half-life (and other parameters) were changing during the target period. The former refers to cases in which the lifetime functions $R_{0}$ and $R$ on the right side of equation (1) represent the same case. On the other hand, in the latter cases, considering the ratio of building stock (existing building floor area) to building inflow (new building floor area) (Supplementary Table S6 and Fig. S1(c)), wooden buildings increased from 1997, and non-wooden buildings increased from 1991, and thus the amount of stock increased relative to inflow. Hence, assuming that building lifetimes clearly fluctuated more than before from 1997 for wooden buildings and from 1991 for non-wooden buildings, we decided to set different halflives (and other parameters) before and after these years. However, since the initial-year building stock consisted of buildings constructed prior to 1964, whether its half-life was the same as that of building stock from 1965 onwards is unknown. Therefore, considering the possibility that initial-year building stock half-lives were different from those of subsequent building stock, we set different half-lives. Based on the above, we categorized wooden buildings into three target periods of 1964, 1965 to 1996, and 1997 to 2020, and non-wooden buildings into three target periods of 1964, 1965 to 1990, and 1991 to 2020, and then examined the half-lives of existing buildings in each period. This means that we divided the lifetime function $R$, the second term on the right side of equation (1), into two periods, and then set three different half-lives (and other parameters) together with the lifetime function $R_{0}$, which is the first term on the right side of equation (1).

\section{Results}

\section{Estimation of lifetime function assuming a single half-life for the target period}

Figure 1 and Supplementary Table S1 show the estimated stock (as predicted by numerous models of lifetime functions) of wooden and nonwooden buildings existing from 1964-2020; these models assumed a single half-life and were constructed with parameters that minimized their residual sum of squares between the statistical observations of building stock [30, 31] and their estimated values. In addition, Fig. 2 and Supplementary Table S2 show the shape of each lifetime function, while Table 1 lists their parameters (such as half-life).

According to the Intergovernmental Panel on Climate Change (IPCC) guidelines [33-35], exponential distribution (which exhibits first-order decay, (FOD)) is recommended for the provisional decay function of semi-finished wood products such as sawn wood and wood-based panels; half-lives of 35,30 , and 25 years were considered in these products. Accordingly, for both wooden and non-wooden buildings, there were large differences between the actual floor area and the FOD estimates based on a 35-year-long half-life - while the estimates of wooden buildings were considerably smaller than their statistical values throughout the entire period, the same trend was particularly observed in nonwooden buildings only from the 1990s (Fig. 1).

Of the six lifetime functions, the estimated Gamma distribution values were particularly divergent from the statistical values for both wooden and non-wooden buildings (Fig. 1), and the shape of the lifetime function was largely different from the other five functions (Fig. 2). For wooden buildings, the minimal residual sum of squares was estimated to be 18 digits in FOD, logistic, normal, log-normal, and Weibull distributions (Table 1). Conversely, for non-wooden buildings, the lifetime function was found to be a log-normal distribution with the least sum of squares of residuals at 17 digits (Table 1 ). 
Table 1

Parameters of lifetime functions (assuming a single half-life).

\begin{tabular}{|c|c|c|c|c|c|c|c|c|c|c|c|c|c|c|}
\hline & \multicolumn{2}{|c|}{ FOD (IPCC) } & \multicolumn{2}{|l|}{ FOD } & \multicolumn{2}{|c|}{ Logistic } & \multicolumn{2}{|c|}{ Normal } & \multicolumn{2}{|c|}{ Log-normal } & \multicolumn{2}{|c|}{ Weibull } & \multicolumn{2}{|c|}{ Gamma } \\
\hline & W & NW & W & NW & W & NW & W & NW & W & NW & W & NW & W & NW \\
\hline Half-life & 35 & 35 & 76 & 46 & 55 & 41 & 58 & 41 & 63 & 78 & 57 & 38 & 45 & 32 \\
\hline $\begin{array}{l}\text { Parameter } \\
1\end{array}$ & - & - & - & - & 0.04 & 0.01 & 51 & 42741 & 1.08 & 2.41 & 1.54 & 1.39 & 32 & 29 \\
\hline $\begin{array}{l}\text { Parameter } \\
2\end{array}$ & - & - & - & - & - & - & - & - & - & - & 72 & 50 & 1.42 & 1.10 \\
\hline $\begin{array}{l}\text { Residual } \\
\text { sum of }\end{array}$ & 3.97E & 4.44E & 8.74E & $5.79 \mathrm{E}$ & $6.11 \mathrm{E}$ & $1.24 \mathrm{E}$ & $5.32 \mathrm{E}$ & $1.23 \mathrm{E}$ & $2.41 \mathrm{E}$ & $5.35 \mathrm{E}$ & $4.46 \mathrm{E}$ & $1.73 \mathrm{E}$ & 1.57E & $1.16 \mathrm{E}$ \\
\hline squares & +19 & +18 & +17 & +17 & +17 & +18 & +17 & +18 & +17 & +16 & +17 & +18 & +19 & +19 \\
\hline
\end{tabular}

Note: "W" and "NW" indicate wooden and non-wooden buildings, respectively, while "Residual sum of squares" denotes the sum of squares of the residuals between the statistical observations of floor area $[30,31]$ and their estimated values.

Estimation of lifetime function assuming multiple half-lives for the target period

Similar to the analysis performed in the previous section, Fig. 3 and Supplementary Table S3 show building stock estimations obtained by assuming multiple half-lives from 1964-2020 (see Methods section) and specifying parameters that minimize the residual sum of squares for each lifetime function. In addition, Fig. 4 and Supplementary Table S4 show the shape of each lifetime function, while Table 2 shows their parameters (such as half-life).

For almost all the lifetime functions of both wooden and non-wooden buildings, the results demonstrate a smaller residual sum of squares upon assuming multiple half-lives than on a single half-life (Tables 1 and 2); this is noteworthy because functions with smaller residuals conform more closely to actual data. However, for wooden buildings, the estimates of Gamma distribution greatly differ from the statistical values (Fig. 3), and the shapes of the normal- and Weibull-distributed lifetime functions (in the 1997-2020 period) are atypical (Fig. 4).

Among the six lifetime functions, the minimal residual sum of squares was found to be 17 digits in the normal, log-normal, and Weibull distributions for wooden buildings. Among these, the log-normal distribution had the least residual sum of squares, making it the most suitable lifetime function. According to the function, the half-lives of wooden buildings existing in 1964, between 1965 and 1996 , and between 1997 and 2020 were 38, 56, and 63 years, respectively (Table 2). Conversely, for non-wooden buildings, the minimal residual sum of squares was estimated to be 17 digits in FOD, normal, and log-normal distributions. Among these, the normal distribution showed the least residual sum of squares. However, it had an atypical shape (Fig. 4) and the estimated parameters were abnormally large (Table 2). By contrast, the lognormal distribution had the second least residual sum of squares and its half-lives of non-wooden buildings existing in 1964 , between 1965 and 1990, and between 1991 and 2020 were 22, 33, and 52 years, respectively. These results confirmed an increase in the lifetime of both wooden and non-wooden buildings over the last 56 years, with wooden buildings having a longer half-life than their non-wooden counterparts. 
Table 2

Parameters of lifetime functions (assuming multiple half-lives).

\begin{tabular}{|c|c|c|c|c|c|c|c|c|c|c|c|c|}
\hline & \multicolumn{2}{|l|}{ FOD } & \multicolumn{2}{|c|}{ Logistic } & \multicolumn{2}{|c|}{ Normal } & \multicolumn{2}{|c|}{ Log-normal } & \multicolumn{2}{|c|}{ Weibull } & \multicolumn{2}{|c|}{ Gamma } \\
\hline & W & NW & W & NW & $\mathbf{W}$ & NW & W & NW & W & NW & $\mathbf{W}$ & NW \\
\hline Half-life (1964) & 373620 & 35 & 56 & 21 & 51 & 19 & 38 & 22 & 42 & 22 & 35 & 8 \\
\hline $\begin{array}{l}\text { Half-life (W: 1965-1996, } \\
\text { NW: 1965-1990) }\end{array}$ & 23 & 33 & 27 & 23 & 26 & 26 & 56 & 33 & 32 & 18 & 98 & 18 \\
\hline $\begin{array}{l}\text { Half-life (W: 1997-2020, } \\
\text { NW: 1991-2020) }\end{array}$ & 21 & 48 & 59 & 41 & 64 & 45 & 63 & 52 & 427 & 34 & 119 & 33 \\
\hline Parameter 1 (1964) & - & - & 0.06 & 0.13 & 22 & 1666 & 0.60 & 1.41 & 2.28 & 2.31 & 12 & 8 \\
\hline $\begin{array}{l}\text { Parameter } 1 \text { (W: 1965- } \\
\text { 1996, } \\
\text { NW: 1965-1990) }\end{array}$ & - & - & 0.10 & 0.10 & 12 & 22 & 0.61 & 1.34 & 4.08 & 3.01 & 33 & 18 \\
\hline $\begin{array}{l}\text { Parameter } 1 \text { (W: 1997- } \\
\text { 2020, } \\
\text { NW: 1991-2020) }\end{array}$ & - & - & 0.10 & 0.07 & 1 & 5063 & 0.20 & 1.53 & 7.00 & 5.74 & 60 & 22 \\
\hline Parameter 2 (1964) & - & - & - & - & - & - & - & - & 49 & 26 & 3.00 & 1.00 \\
\hline $\begin{array}{l}\text { Parameter } 2 \text { (W: 1965- } \\
\text { 1996, } \\
\text { NW: 1965-1990) }\end{array}$ & - & - & - & - & - & - & - & - & 35 & 20 & 3.00 & 1.00 \\
\hline $\begin{array}{l}\text { Parameter } 2 \text { (W: 1997- } \\
\text { 2020, } \\
\text { NW: 1991-2020) }\end{array}$ & - & - & - & - & - & - & - & - & 450 & 36 & 2.00 & 1.50 \\
\hline Residual sum of squares & $1.44 \mathrm{E}$ & $7.54 \mathrm{E}$ & $1.44 \mathrm{E}$ & $1.90 \mathrm{E}$ & $4.98 \mathrm{E}$ & $6.58 \mathrm{E}$ & $2.13 \mathrm{E}$ & $6.79 \mathrm{E}$ & $6.08 \mathrm{E}$ & $6.70 \mathrm{E}$ & $2.90 \mathrm{E}$ & 7.42E \\
\hline & +17 & +16 & +17 & +17 & +16 & +16 & +16 & +16 & +16 & +17 & +18 & +17 \\
\hline
\end{tabular}

\section{Carbon stock estimation in building wood}

The wood carbon stock in the buildings (wooden and non-wooden), as shown in Fig. 5 and Supplementary Table S5, was estimated using their half-lives by adopting a log-normal distribution (corresponding to multiple half-lives during the period under study) for the lifetime function (see Methods section). The carbon stock in wooden buildings increased from $106 \mathrm{Tg}-\mathrm{C}$ in 1964 to 214 Tg-C in 2020 , a nearly twofold growth over the past 56 years. The carbon stock in non-wooden buildings, on the other hand, increased from 2 to $27 \mathrm{Tg}-\mathrm{C}$ over the same period. Adding these values, the total carbon stock in wooden and non-wooden buildings in 2020 was estimated to be $241 \mathrm{Tg}-\mathrm{C}$, of which $89 \%$ was contributed by wooden buildings and $11 \%$ by non-wooden ones.

\section{Discussion}

The exponential distributions of semi-finished wood products (such as sawn wood and wood-based panels), as proposed in the IPCC guidelines [33-35] with singular half-life values (between 25-35 years), underestimate building stock along with the associated carbon stock and are, therefore, ill-suited to the lifetime distribution of buildings in Japan. In this paper, we have presented the estimated results for a half-life of 35 years [34, 35]; this value has been chosen because at half-lives of 30 [33] or 25 [34, 35] years, the residual sum of squares may increase further.

A more suitable estimation of the lifetime function during the target period of 1964-2020 was achieved by setting three different half-lives rather than one; this is a better characterization of building lifetimes in Japan. Building stock in 1964 is believed to include buildings built from the Edo period to the Showa period. During this era, Japan underwent tremendous social and cultural transformation as well as witnessed technological development while experiencing multiple wars in which urban areas in major cities were devastated by air raids [36]; thus, 
building-life distribution in this era is considered to be markedly different from that of contemporary times. In addition, many wooden buildings in Japan are residential, while many non-wooden buildings are middle-high-rise constructions that house office complexes, commercial facilities, or factories [37]. Japanese society saw a dramatic jump in stock and real estate prices during the late 1980s, which fell sharply in 1991, triggering a long-term recession [38]. Worsening economic conditions reduced the demand for new non-wooden buildingsmainly offices, commercial facilities, and factories-which may have prolonged building lifetimes. Furthermore, 1997 witnessed an increase in the taxes levied on consumption [39]; it is conjectured that the resulting economic stagnation hindered the construction of new wooden buildings and further extended building lifetimes. These factors may have particularly prolonged the half-lives of non-wooden and wooden buildings from 1991 and 1997, respectively. In addition, Japan experiences frequent earthquakes; the Building Standards Act was revised in 1981 and 2000 to have stricter seismic standards [40]. Improvements made to the seismic performance of buildings in compliance with these standards may have led to longer building lifetimes in the long run.

It appears that in addition to the log-normal distribution, other distributions (excluding the Gamma distribution) are valid as lifetime functions of wooden buildings. However, in the case of FOD, building half-life in 1964 is inordinately long and shortens with the passage of time, which, as mentioned above, cannot be reasonably explained from Japan's socioeconomic situation during this period. Similar doubts undermine the validity of logistic distribution as a valid lifetime function, as the half-life from 1965 to 1996 becomes shorter than that in 1964. In addition, the shape of the lifetime function for the normal distribution from 1997 to 2020 is clearly unnatural, and the half-life of the Weibull distribution from 1997 to 2020 is abnormally long. From these aspects, the log-normal distribution was inferred to be the most suitable lifetime function of wooden buildings; this is supported by the minimal residual sum of squares, their half-life values, and the validity of their distribution curves. Conversely, for non-wooden buildings, the normal distribution, owing to its atypical linear shape and the abnormally large parameters, as mentioned earlier, cannot be supported as an appropriate lifetime distribution. By contrast, the log-normal distribution was found to be a suitable lifetime function from the viewpoint of residual sum of squares, half-life values, and the distribution shape. Importantly, unlike wooden buildings, for non-wooden buildings, FOD is also suitable as a lifetime function for similar factors, with log-normal distribution resembling the shape of FOD. Thus, we can infer that non-wooden buildings carry characteristics of exponential lifetime distribution. Therefore, these buildings, which are often offices or commercial facilities, may be excluded immediately after construction to a certain degree.

Here, we compare the lifetime functions estimated by existing works of research in Japan and abroad, as well as in this study. The exponential $[3,10,13,33-35]$, normal $[1,2,12,14,16]$, and Weibull distributions $[9,12,14,17-20]$ are internationally well-known lifetime functions. Japanese studies, on the other hand, have favored the log-normal [12, 21-23, 26, 41, 42] and Weibull distributions [12, 21-23, 42]. In this study, the log-normal distribution proved to be the most suitable for wooden buildings, and the log-normal distribution resembling FOD was the most apt for non-wooden buildings. While our results on wooden buildings conforms with past research, our findings on non-wooden buildings do not. However, this can be explained by the fact that past studies focused only on urban centers and not on all of Japan [12, 2123]; further, they studied wooden and non-wooden buildings together without differentiating between them [26]. Additionally, these studies have not used the latest data published in 2020.

When we compare the results for half-lives between past research and this study, the yearly half-lives of wooden housing in major Japanese cities were reportedly in the 30s during the 1980s [21-23], around 40 during the 1990s [23, 24], and around 50 in the early 2000s [23, 24]. In this study, the half-life of existing wooden buildings was 56 years between 1965 and 1996 and 63 years between 1997 and 2020 . This tendency of building lifetimes to lengthen with the passage of time has been established in both previous works and in this study. However, the results of past research are mainly for urban areas with robust economic activity; hence, this study, which covered all of Japan (including rural areas), reported longer half-lives. In fact, past research on buildings in Tokyo [21] and Nagoya [12], which are major Japanese cities, show half-lives shorter than 30 years. On the other hand, the half-lives of non-wooden buildings in multiple cities in Japan were reportedly in the 30 s during the 1980s [22], 33 to 51 years in the 1990s [24], and 41 to 58 years in the 2000s [24]. In this study, half-lives were 33 years from 1965 to 1990 and 52 years from 1991 to 2020; thus, the half-life values and lengthening lifetimes were both consistent. In addition, it is estimated that the half-lives of wooden and non-wooden buildings, considered as an undifferentiated entity and taken throughout Japan, were about 40 years, or between 55 and 80 years [26] from 1945 to 1991. In this study, the half-life of wooden buildings that existed between 1965 and 1996 was estimated at 56 years, and the half-life of non-wooden buildings between 1965 and 1990 was estimated to be 33 years, indicating a shorter half-life for non-wooden buildings than that estimated in past research. However, the non-wooden stock during this period was smaller than the wooden stock (see Supplementary Table S6 and Fig. S1(a)); hence, the effect that the lifetime of non-wooden buildings had on buildings as a whole was minimal. On the other hand, past research has reported the half-life of buildings to range from 61 to 100 years in the United States [8, 9, 11], 80 years in the United Kingdom [8, 12], 125 years in Norway [14], 65 to 150 years in Germany [8, 16], 100 years in Czech Republic [16], and 80 to 150 years in Austria [17], indicating building lifetimes in Europe and the US to be considerably longer than those in Japan. In contrast, the half-life of buildings in China was reportedly approximately 30 years from 1950 to 2017 [19, 20 ], which is considerably shorter than those of Japan, the US, and Europe. 
The non-wooden building stock in Japan continued to increase from 1964, and from 2011, it exceeded the wooden building stock (Supplementary Table S6 and Fig. S1(a)). However, approximately $90 \%$ of the carbon stock in building wood is derived from wooden buildings, which are still a primary representative of carbon storage. The latest carbon stock in all buildings as of 2020 was $241 \mathrm{Tg}-\mathrm{C}$, which is equal to $8 \%-9 \%$ of the amount of carbon stock [43] in Japan's forest biomass - a size that cannot be ignored when examining current and future carbon balance in forest sinks.

\section{Concluding Remarks}

In this study, we used statistical data from 1964 to 2020 to estimate the lifetime distribution of wooden and non-wooden buildings throughout Japan.

The results indicated a log-normal distribution to be the most suitable lifetime function for wooden buildings; this was in conformance with results from past research on multiple urban areas in Japan. However, in this study, the half-life of wooden buildings was estimated to be 38 years in 1964, 56 years from 1965 to 1996, and 63 years from 1997 to 2020, and it is evident from estimates based on the latest nationwide data on Japan that wooden buildings have longer lifetimes than those reported in previous research.

Although we found that the log-normal distribution is the most suitable lifetime function for non-wooden buildings, the shape of the distribution resembled that of the exponential distribution. It is highly likely that non-wooden buildings, which are often commercial facilities, offices, and factories, may have different lifetime distributions from wooden buildings, which are primarily residential. The half-life of nonwooden buildings was estimated to be 22 years in 1964, 33 years from 1965 to 1990, and 52 years from 1991 to 2020, and thus lengthened over the past half-century, similar to wooden buildings.

The carbon stock in building wood increased more than $100 \%$ over the past half-century and was estimated at $241 \mathrm{Tg}-\mathrm{C}$ in 2020 ; of this, $89 \%$ was contributed by wooden buildings and the remaining $11 \%$ by non-wooden buildings.

It is important for future research to use these findings of the lifetime function and half-life of wooden and non-wooden buildings to present future predictions of building stock flow and implement measures to effectively mitigate climate change; such action will need to be taken based on policy scenarios related to the demand for new buildings and changes in building lifetime.

\section{Declarations}

\section{Data Availability}

The datasets generated and analyzed during the current study are available from the corresponding author on reasonable request.

\section{Acknowledgements}

This research was supported by the Japan Society for the Promotion of Science (grant number JP20H04384) and Research Grant of the Forestry and Forest Products Research Institute (grant number 202101).

\section{Author contributions}

C.K. and M.T. conceptualized and designed this study, analyzed data, and prepared figures and tables. C.K. wrote the main manuscript text. M.T. edited the text. All authors reviewed the manuscript.

\section{Additional Information}

The authors declare no competing interests.

Supplementary information is available for this paper on the Web.

Correspondence and requests for materials should be addressed to C.K.

\section{References}


1. Fishman, T., Schandl, H., Tanikawa, H., Walker, P. \& Krausmann, F. Accounting for the material stock of nations. J. Ind. Ecol, 8 (3), $407-420$ https://doi.org/10.1111/jiec.12114 (2014).

2. Krausmann, F. et al. Global socioeconomic material stocks rise 23-fold over the 20th century and require half of annual resource use. PNAS, 114 (8), 1880-1885 https://doi.org/10.1073/pnas.1613773114 (2017).

3. Marland, E. S., Stellar, K. \& Marland, G. H. A distributed approach to accounting for carbon in wood products. Mitig. Adapt. Strateg. Glob. Change, 15, 71-91 https://doi.org/10.1007/s11027-009-9205-6 (2010).

4. Kayo, C., Tsunetsugu, Y. \& Tonosaki, M. Climate change mitigation effect of harvested wood products in regions of Japan. Carbon Balance Manage, 10, 24 https://doi.org/10.1186/s13021-015-0036-3 (2015).

5. Kayo, C. et al. Environmental impact assessment of wood use in Japan through 2050 using material flow analysis and life cycle assessment. J. Ind. Ecol, 23 (3), 635-648 https://doi.org/10.1111/jiec.12766 (2019).

6. Churkina, G. et al. Buildings as a global carbon sink. Nat Sustain, 3, 269-276 https://doi.org/10.1038/s41893-019-0462-4 (2020).

7. Zhang, X., Chen, J., Dias, A. C. \& Yang, H. Improving carbon stock estimates for in-use harvested wood products by linking production and consumption - a global case study. Environ. Sci. Technol, 54, 2565-2574 https://doi.org/10.1021/acs.est.9b05721 (2020).

8. Pingoud, K., Perl, A-L., Soimakallio, S. \& Pussinen, A. Greenhouse gas impacts of harvested wood products: Evaluation and development of methods.VTT Research Notes2189, VTT Information Service, http://www.vtt.fi/inf/pdf/tiedotteet/2003/T2189.pdf (2003).

9. Kapur, A., Keoleian, G., Kendall, A. \& Kesler, S. E. Dynamic modeling of in-use cement stocks in the United States. J. Ind. Ecol, 12, 539-556 https://doi.org/10.1111/j.1530-9290.2008.00055.x (2008).

10. Marland, E. \& Marland, G. The treatment of long-lived, carbon-containing products in inventories of carbon dioxide emissions to the atmosphere. Environ. Sci. Policy, 6 (2), 139-152 https://doi.org/10.1016/S1462-9011(03)00003-0 (2003).

11. Aktas, C. B. \& Bilec, M. M. Impact of lifetime on US residential building LCA results. Int. J. Life Cycle Assess, 17, 337-349 https://doi.org/10.1007/s11367-011-0363-x (2012).

12. Miatto, A., Schandl, H. \& Tanikawa, H. How important are realistic building lifetime assumptions for material stock and demolition waste accounts? Resour. Conserv. Recycl, 122, 143-154 https://doi.org/10.1016/j.resconrec.2017.01.015 (2017).

13. Pingoud, K., Perälä, A. L. \& Pussinen, A. Carbon dynamics in wood products. Mitig. Adapt. Strateg. Glob. Change, 6, 91-111 https://doi.org/10.1023/A:1011353806845 (2001).

14. Sandberg, N. H., Sartori, I. \& Bratteb $\varnothing$, H. Using a dynamic segmented model to examine future renovation activities in the Norwegian dwelling stock. Energy Build, 82, 287-295 https://doi.org/10.1016/j.enbuild.2014.07.005 (2014).

15. Bradley, E. P. \& Kohler, N. Methodology for the survival analysis of urban building stocks. Build. Res. Inf, 35, 529-542 https://doi.org/10.1080/09613210701266939 (2007).

16. Vásquez, F., Løvik, A. N., Sandberg, N. H. \& Müller, D. B. Dynamic type-cohort-time approach for the analysis of energy reductions strategies in the building stock. Energy Build, 111, 37-55 https://doi.org/10.1016/j.enbuild.2015.11.018 (2016).

17. Kalcher, J., Praxmarer, G. \& Teischinger, A. Quantification of future availabilities of recovered wood from Austrian residential buildings. Resour. Conserv. Recycl, 123, 143-152 https://doi.org/10.1016/j.resconrec.2016.09.001 (2017).

18. Cai, W., Wan, L., Jiang, Y., Wang, C. \& Lin, L. Short-lived buildings in China: Impacts on water energy, and carbon emissions. Environ. Sci. Technol, 49 (24), 13921-13928 https://doi.org/10.1021/acs.est.5b02333 (2015).

19. Cao, Z. et al. Unravelling the mystery of Chinese building lifetime: A calibration and verification based on dynamic material flow analysis. Appl. Energy, 238, 442-452 https://doi.org/10.1016/j.apenergy.2019.01.106 (2019).

20. Zhou, W., Moncaster, A., Reiner, D. M. \& Guthrie, P. Estimating lifetimes and stock turnover dynamics of urban residential buildings in China. Sustainability, 11 (13), 3720 https://doi.org/10.3390/su11133720 (2019).

21. Komatsu, Y. Some theoretical studies on making a life table of buildings. J. Archit. Plann. Environ. Eng., AlJ., 439, 91-99(1992).

22. Komatsu, Y., Kato, Y., Yoshida, T. \& Yashiro, T. Report of an investigation of the life time distribution of Japanese houses at 1987 estimation based on the ledgers of buildings for fixed property taxes. J. Archit. Plann. Environ. Eng., AlJ, 439, 101-110 (1992).

23. Tsutsumi, H. \& Komatsu, Y. Transition of the lifetime of wooden houses since 1980. J. Archit. Plann., AlJ, 580, 169-174 (2004).

24. Komatsu, Y. Life time estimations of Japanese buildings and houses at the years of 1997 and 2005. J. Archit. Plann., AlJ, 632, 21972205 (2008).

25. Tanikawa, H. \& Hashimoto, S. Urban stock over time: spatial material stock analysis using 4d-GIS. Build. Res. Inf, 37, 483-502 https://doi.org/10.1080/09613210903169394 (2009).

26. Yashiro, T. Analysis on past building stock formation using life distribution model obtained from building activity statistics. J. Archit. Plann. Environ. Eng., AlJ, 464, 151-160 (1994). 
27. Hashimoto, S. \& Moriguchi, Y. Data book: material and carbon flow of harvested wood in Japan. CGER-REPORT D034-2004, National Institute for Environmental Studies, https://www.cger.nies.go.jp/publications/report/d034/D034.pdf (2004).

28. Tsunetsugu, Y. \& Tonosaki, M. Quantitative estimation of carbon removal effects due to wood utilization up to 2050 in Japan: effects from carbon storage and substitution of fossil fuels by harvested wood products. J. Wood Sci, 56, 339-344 https://doi.org/10.1007/s10086-009-1107-4 (2010).

29. Matsumoto, R. \& Kayo, C. Carbon stocks in harvested wood products used in buildings in Japanese Prefectures. Mokuzai Gakkaishi, 67 (3), 138-148 https://doi.org/10.2488/jwrs.67.138 (2021).

30. Japan Ministry of Internal Affairs and Communications.Summary Report on Prices of Fixed Assets(1965).

31. Japan Ministry of Internal Affairs and Communications. Summary Report on Prices of Fixed Assets (1966-2021).

32. Japan Ministry of Land, Infrastructure, Transport and Tourism. Report on Statistical Survey of Building Starts (1965-2021).

33. Intergovernmental Panel on Climate Change (IPCC). 2006 IPCC Guidelines for National Greenhouse Gas Inventories. National Greenhouse Gas Inventories Programme, Institute for Global Environmental Strategies (2006).

34. IPCC. 2013 Revised Supplementary Methods and Good Practice Guidance Arising from the Kyoto Protocol. IPCC (2014).

35. IPCC. 2019 Refinement to the 2006 IPCC Guidelines for National Greenhouse Gas Inventories, IPCC (2019).

36. Kato, Y. Japan's Modern History of War (Kodansha, 2002).

37. Japan Forestry Agency. FY2020 White Paper on Forest and Forestry (2021).

38. Komine, T. Heisei Economics (Nihon Keizai Shinbun Publishing Company, 2019).

39. Morinobu, S.. Japan's consumption tax - History and critical materials on its introduction and revision (Tax Payment Associations, 2000).

40. Otani, S. Changes in seismic standards for building structures. Concrete J, 41 (5), 11-16 https://doi.org/10.3151/coj1975.41.5_11 (2003).

41. Hashimoto, S., Tanikawa, H. \& Moriguchi, Y. Where will large amounts of materials accumulated within the economy go? - a material flow analysis of construction minerals for Japan. Waste Manage, 27, 1725-1738 https://doi.org/10.1016/j.wasman.2006.10.009 (2007).

42. Tanikawa, H., Fishman, T., Okuoka, K. \& Sugimoto, K. The weight of society over time and space: a comprehensive account of the construction material stock of Japan, 1945-2010. J. Ind. Ecol, 19 (5), 778-791 https://doi.org/10.1111/jiec.12284 (2015).

43. Egusa, T., Kumagai, T. \& Shiraishi, N. Carbon stock in Japanese forests has been greatly underestimated. Sci. Rep, 10,7895 https://doi.org/10.1038/s41598-020-64851-2 (2020).

44. Ministry of Land, Infrastructure, Transport and Tourism. Survey on Labor Demand and Construction Materials (Building Sector) (19782019).

\section{Figures}




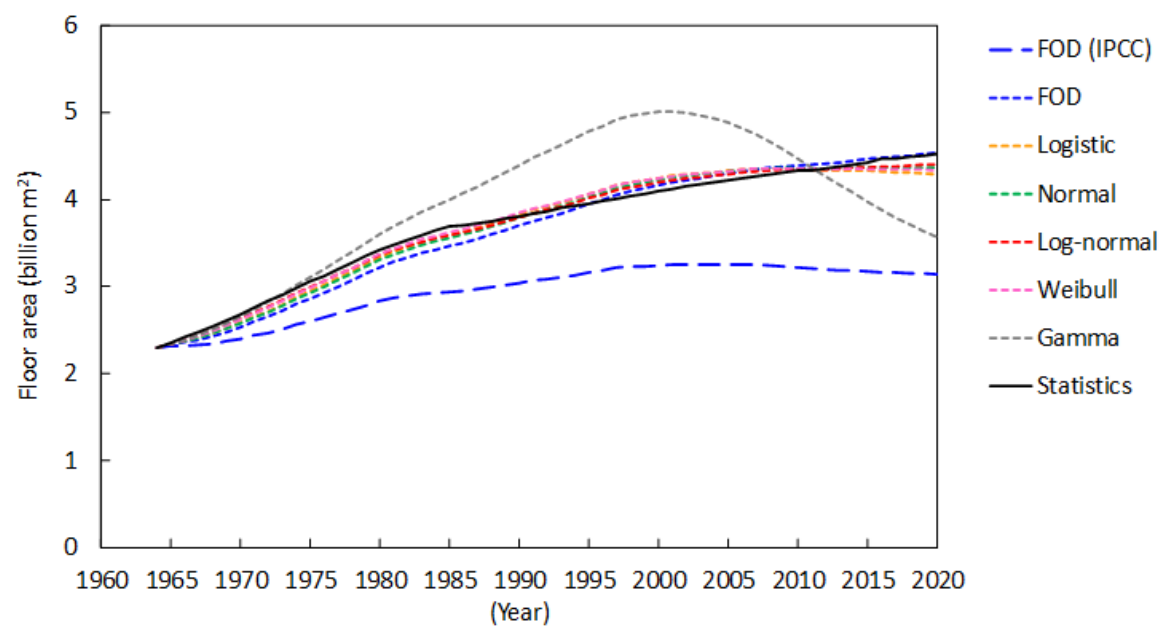

(a) Wooden buildings

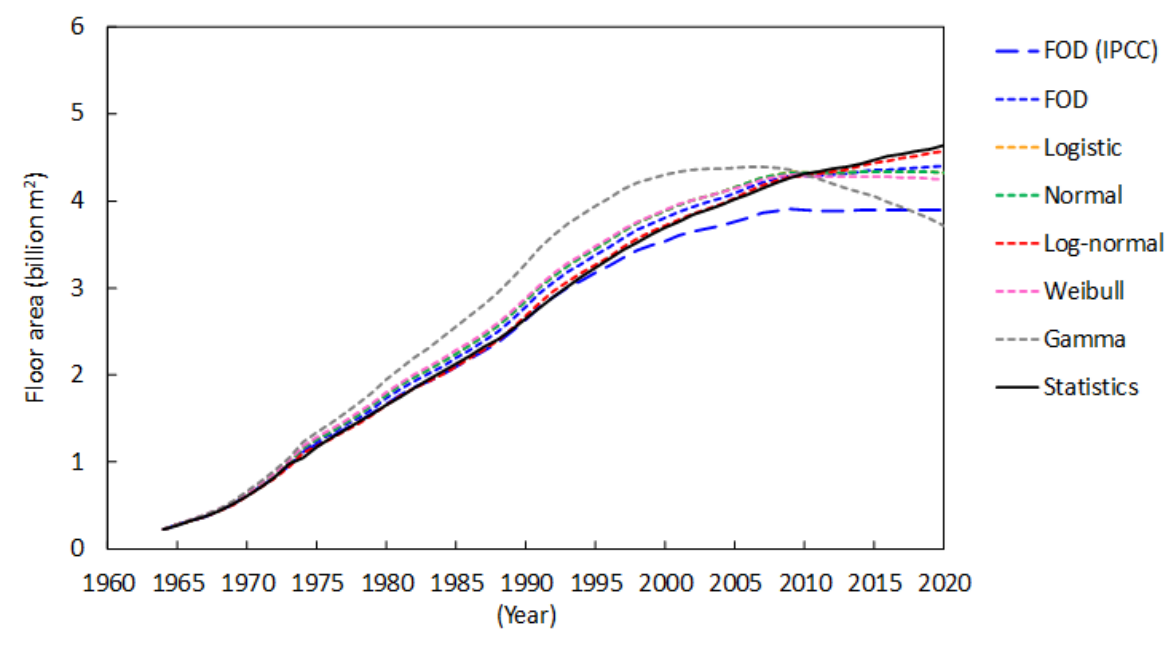

(b) Non-wooden buildings

\section{Figure 1}

Floor-area estimates of each lifetime function, assuming a single half-life throughout the entire period. "FOD (IPCC)" indicates, in accordance with the first order decay (FOD) lifetime function provisionally recommended in IPCC guidelines, the estimates corresponding to a half-life of 35 years [34,35], while "FOD," "Logistic," "Normal," "Log-normal," "Weibull", and "Gamma" indicate the floor-area estimates of these functions based on parameters that minimize the residual sum of squares; "Statistics", on the other hand, indicates the actual recorded values [30, 31]. 

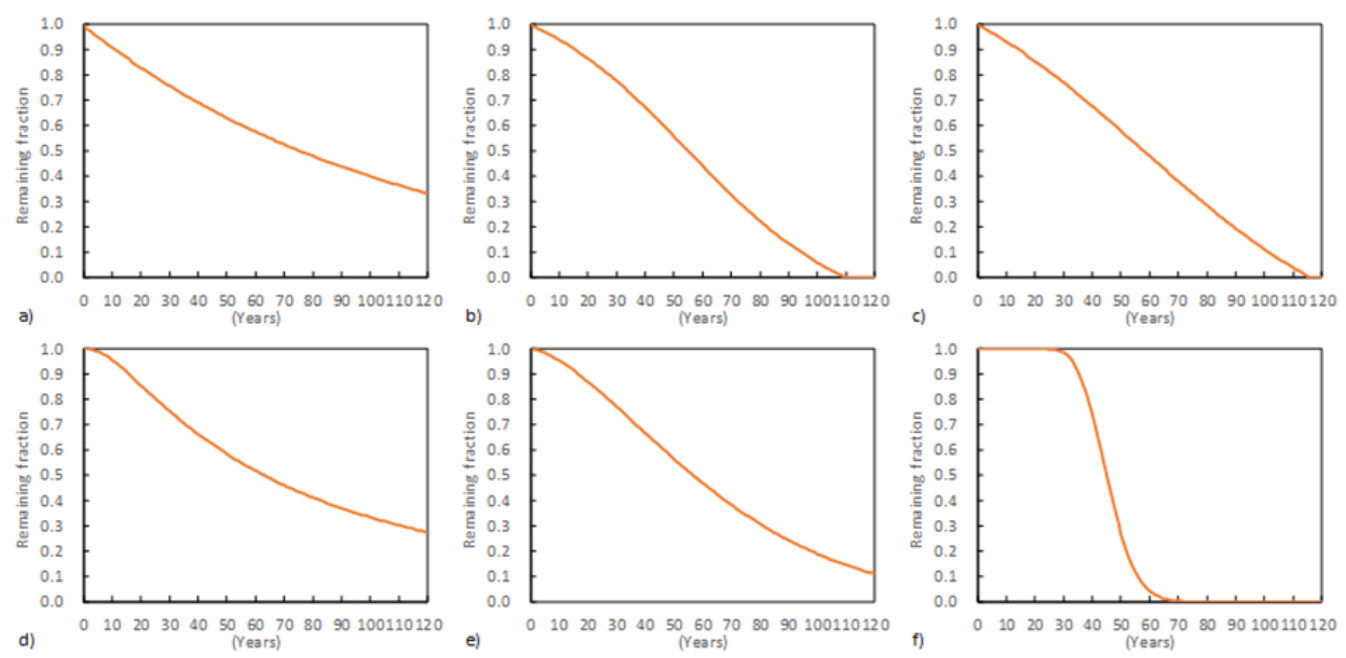

(a) Wooden buildings
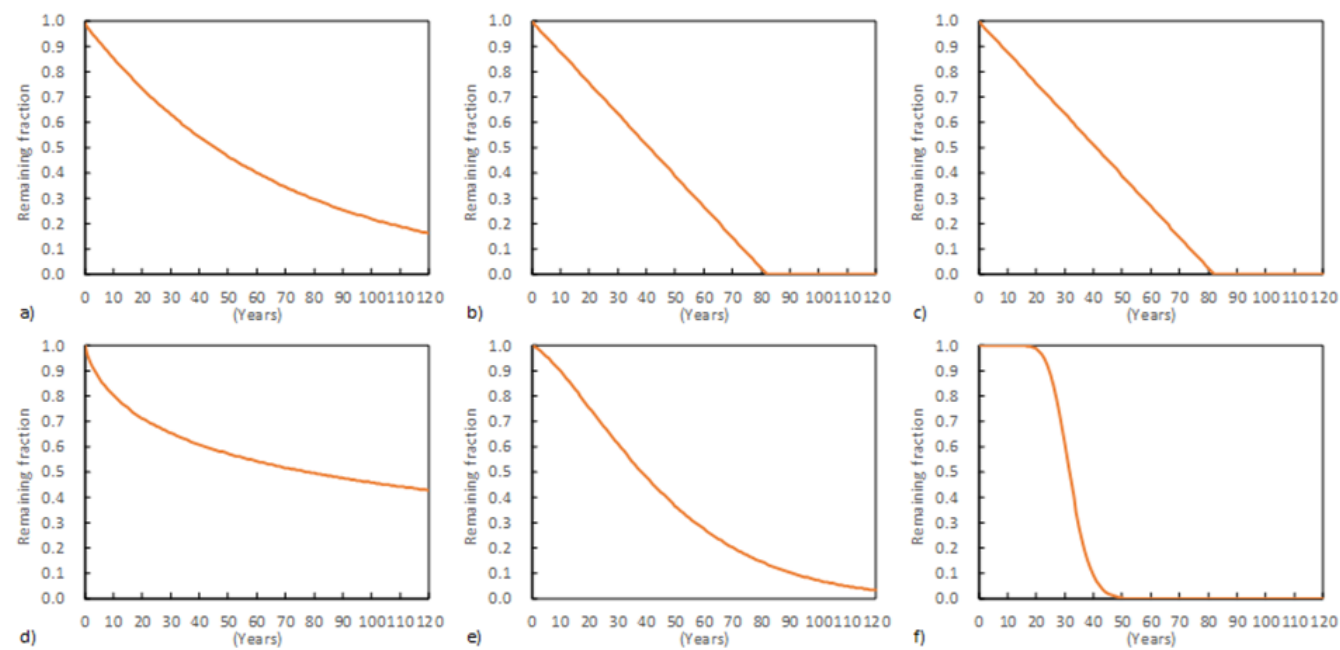

(b) Non-wooden buildings

\section{Figure 2}

Shape of each lifetime function, assuming a single half-life throughout the entire period. a) Exponential distribution, b) logistic distribution, c) normal distribution, d) log-normal distribution, e) Weibull distribution, and f) Gamma distribution. The shape of each lifetime function corresponds to the estimations in Fig. 1. 


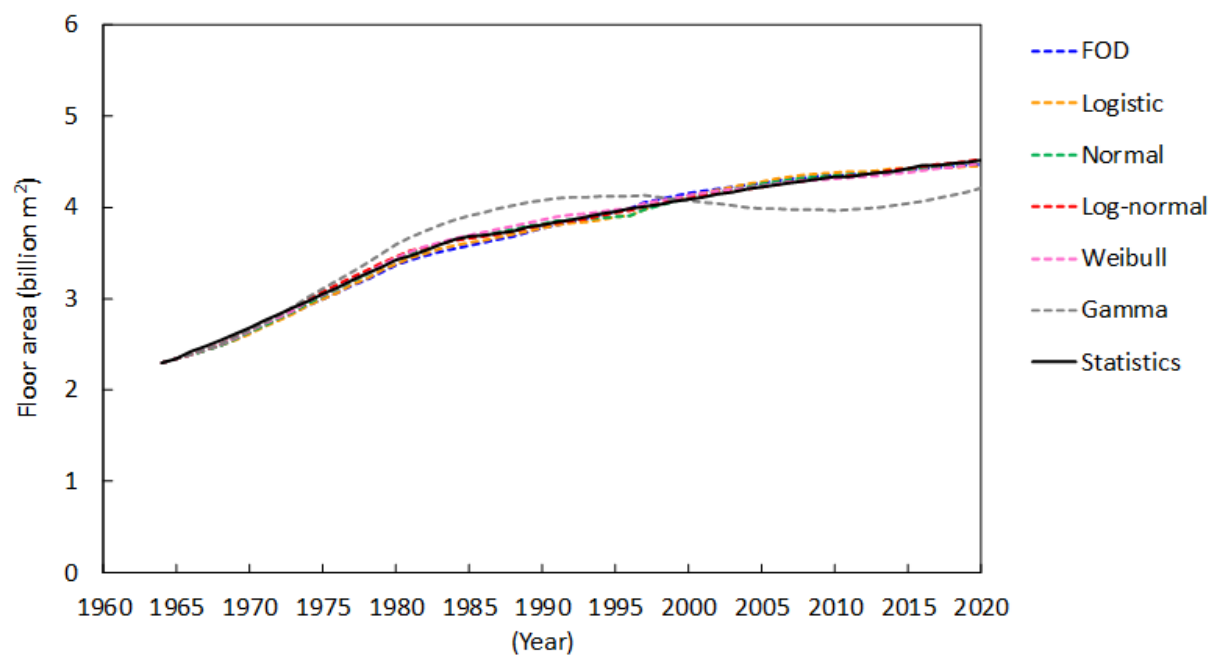

(a) Wooden buildings

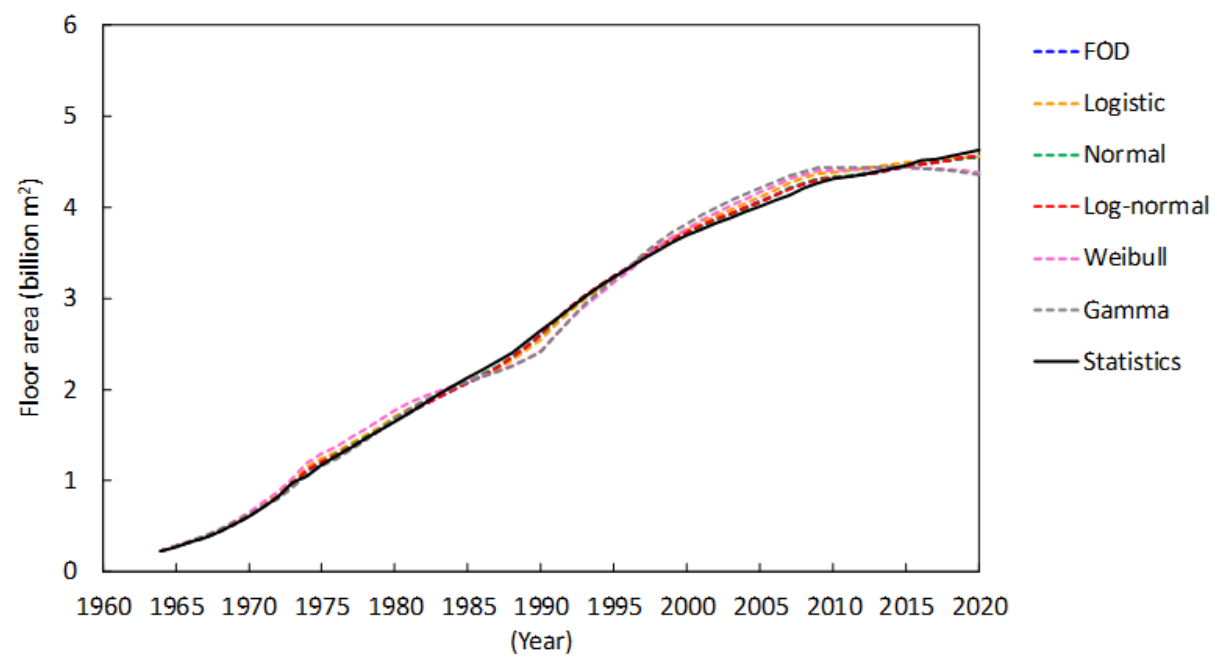

(b) Non-wooden buildings

\section{Figure 3}

Floor-area estimates of each lifetime function, assuming multiple half-lives throughout the entire period. "FOD," "Logistic," "Normal," "Lognormal," "Weibull," and "Gamma" indicate the estimations of these functions based on parameters that minimize the residual sum of squares; "Statistics", on the other hand, indicates the actual recorded values [30, 31]. 

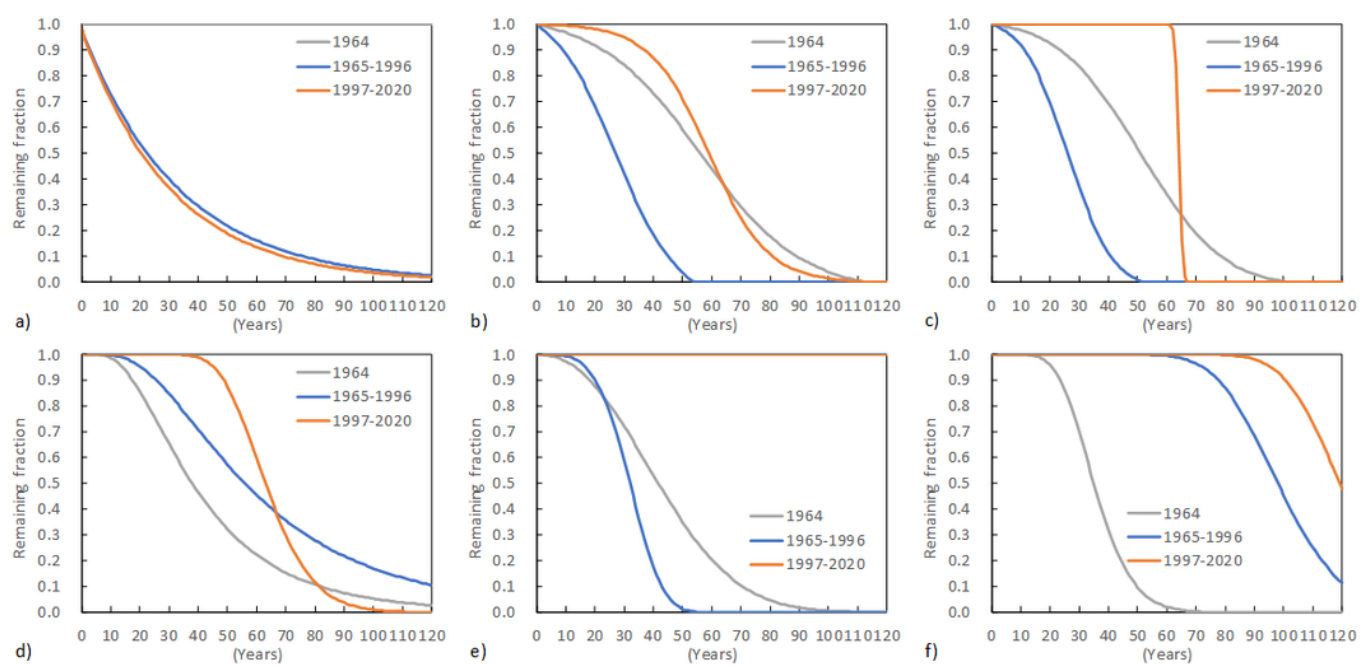

(a) Wooden buildings
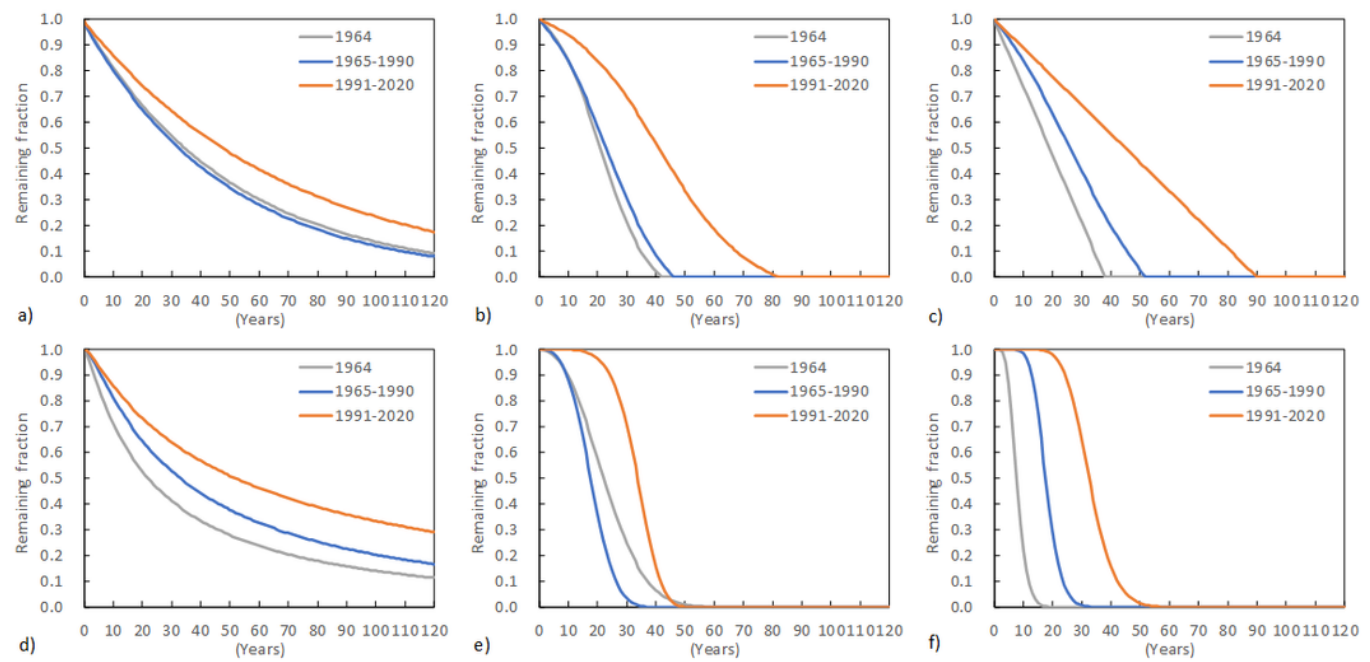

(b) Non-wooden buildings

\section{Figure 4}

Shape of each lifetime function, assuming multiple half-lives throughout the entire period. a) Exponential distribution, b) logistic distribution, c) normal distribution, d) log-normal distribution, e) Weibull distribution, and f) Gamma distribution. "1964", "1965-1996", "1965-1990", "1997-2020", and "1991-2020" indicate buildings that existed during those years. All these shapes correspond to the estimations shown in Fig. 3. 


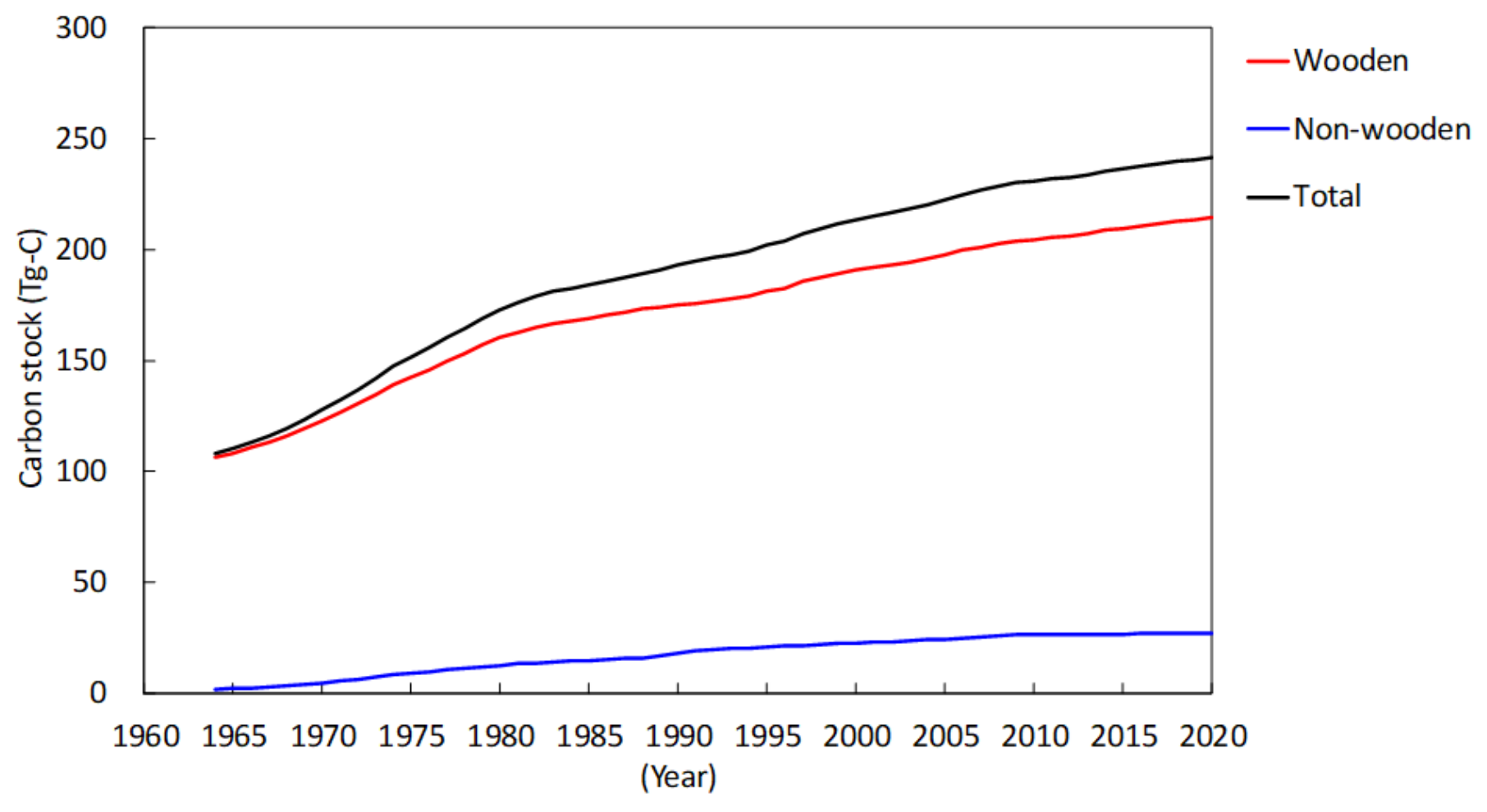

Figure 5

Carbon stock estimations in building wood.

\section{Supplementary Files}

This is a list of supplementary files associated with this preprint. Click to download.

- SupplementaryInformation.xlsx 